\title{
REALIZAÇÃO E RECEPÇÃO: UM EXERCÍCIO DE LEITURA
}

\section{Análise de vídeo a partir de palavras geradoras permite aos receptores um exercício de leitura repleto de descobertas}

A experiência na realização de um vídeo, mesmo com objetivo e público-alvo determinados, normalmente é distanciada da experiência do seu uso. Quem realiza tem o domínio sobre determinados códigos da linguagem específica do meio, os quais são comumente desconhecidos do receptor que, por seu lado, possui determinadas formas de compreensão muitas vezes desconsideradas pelo realizador.

Este texto se propõe a apresentar o relato de uma experiência de recepção com o vídeo $O$ palácio da memória ${ }^{1}$, realizada com um grupo de educadores que participou, em 1995, do evento vídeo-debate ${ }^{2}$. O vídeo trata de recursos pedagógicos e foi produzido com o objetivo de colaborar para a formação de educadores. Com base no processo de elaboração do vídeo, realizamos, a partir de palavras aleatórias que surgiram na platéia, uma dinâmica de desmontagem do filme.

Não se trata de uma análise aprofundada dessa experiência, mas do esboço de algumas idéias que possam servir como ponto de partida para o seu futuro desenvolvimento, a fim de criar condições para o que poderíamos chamar de uma relação de interlocução, diálogo e interação entre os participantes de um grupo de aprendizagem, utilizando o cinema ou o vídeo como recurso pedagógico, para permitir uma construção compartilhada do conhecimento.

\section{PONTO DE VISTA DA REALIZAÇÃO}

Efetuar através do vídeo $O$ palácio da memória uma mera apresentação dos recursos pedagógicos seria como mostrar os instrumentos sem nenhuma significação, desvinculados do processo educativo e dos princípios que o norteiam. Por isso, o vídeo foi realizado com o objetivo de despertar no educador o desejo de conhecer novas técnicas e novos recursos, propondo-se, ao mesmo tempo, a estimular um pensamento crítico sobre o tema.

No roteiro inicial, a referência a alguns recursos como o livro, o quadro, a tela do vídeo e a tela de um microcomputador funcionam como ícones marcadores do caminho, todos aprisionados no armazém do computador, espaço do palácio da memória, como uma metáfora da mente, uma sugestão de que as idéias desenvolvidas passam para a memória - mente, palácio, computador.

\section{A AUTORA}

Maria Teresa Azevedo da Fonseca

Professora de Cinema na Universidade Metodista de Piracicaba e realizadora de vídeos.

1. O palácio da memória (Vídeo); duração: 18min.; produção: Centro Internazionale Crocevia/ TVT/ Instituto Cajamar, 1994; roteiro e direção: Maria Teresa Azevedo Fonseca (Marithê); elenco: Luís Mello, Eduardo Silva, Rosi Campos, participação de Paulo Freire.

2. O evento aconteceu no Sesc Piracicaba em maio de 1995, com um grupo formado por 27 educadores, participantes do vídeo-debate. 
A idéia era a de fazer um vídeo que não fosse complexo demais a ponto de os professores se sentirem em dificuldades para dialogar com ele, e nem aleatório demais para não correr o risco de se tornar dispersivo. Ele precisava ser, à primeira vista, de fácil compreensão, mas que exigisse do espectador uma atenção especial e despertasse inquietação suficiente para provocar um debate. Num primeiro plano, elementos facilmente identificáveis, num segundo plano, espaços sugeridos para a criação de um intertexto.

\section{$O$ vídeo inicia-se com um plano deta-} lhe da mão de um jesuíta acendendo uma lamparina que percorre corredores: a chama, conhecimento que ilumina, o corredor, caminho a ser percorrido. Transpondo o tempo, a experiência de um recurso mnemônico, que os jesuítas usavam no século XVI, é relatado pelo personagem: um palácio imaginário, cheio de compartimentos onde se colocavam imagens e idéias, que eram acionadas, para construir as cadeias do pensamento.

Vygotsky e Bakhtin ${ }^{3}$ consideram a palavra fundamental para o desenvolvimento do pensamento e da consciência, incluindose aí o fenômeno do discurso interior. Na visão destes autores, a elaboração cognitiva é processada através de uma dinâmica interativa, o sujeito é constituído na sua relação com os outros, ou seja, a construção da subjetividade passa pelo discurso interior, que é onde se desenvolve o pensamento, sugerindo a estreita relação entre pensamento e lin- guagem. "O processo de internalização é eminentemente dialógico porque aquilo que eu internalizo, o intrapsicológico, só acontece a partir de uma interação, do interpsicológico, portanto sendo indispensável o papel do outro"4.

Esse processo interativo entre mundo externo e mundo interno, entre o social e o individual, entre eu e o(s) outro(s) é articulado através do diálogo. "É no quadro do discurso interior que se efetua a apreensão da enunciação de outrem, sua compreensão e sua apreciação"s.

Vygotsky observa no discurso interior a preponderância do sentido adquirido no contexto de uso de uma palavra sobre seu significado cristalizado socialmente. $\mathrm{O}$ sentido se revela dentro de um contexto e a mesma palavra pode ter vários sentidos de acordo com aquele que a expressa: "o sentido de uma palavra é a soma de todos os eventos psicológicos que a palavra desperta em nossa consciência" 6 .

Para Vygotsky, o processo de internalização é mnemônico e a chave deste processo está na mediação: "em um sentido amplo, mediação é toda intervenção de um terceiro elemento que possibilita a interação entre os termos de uma relação" "?.

$\mathrm{O}$ discurso interior, como foi pensado por Vygotsky, influenciou o cineasta Serguei Eisenstein na elaboração de sua teoria da montagem. Ele chama esse cinema de intelectual. Faz pensar e se expressa na forma, com as mesmas estruturas do pensamento, concluindo assim que montar é pensar: "Porque a forma de montagem, como estru-

3. VYGOTSKY, L. S. Pensamento e linguagem. São Paulo: Martins Fontes, 1993. Formação social da mente. São Paulo: Martins Fontes, 1991. BAKTHIN, Mikhail. Marxismo e filosofia da linguagem. São Paulo: Hucitec, 1992.

4. FREITAS, Maria Teresa A. O pensamento de Vygotsky e Bakthin no Brasil. Campinas: Papirus, 1994 . p.93.

5. BAKTHIN, Mikhail. Marxismo... op. cit. p.147.

6. PAULHAN. Apud VYGOTSKY, L. S. Pensamento e linguagem, op. cit. p. 125.

7. PINO, Angel. O conceito de mediação semiótica em Vygotsky e o seu papel na explicação do psiquismo humano. Cadernos CEDES. São Paulo, n.24, 1991. p.32. 
tura, é uma reconstrução das leis do processo de pensamento"8.

Eisenstein, Vygotsky e Bakthin viveram na mesma época, no mesmo país, compartilharam uma visão de mundo influenciada pela efervescência pós-revolução russa nos anos 20, e a possibilidade de criação de um novo homem. A busca de Eisenstein por um cinema pedagógico o faz também refletir sobre linguagem e pensamento, tendo como uma das referências o discurso interior. "O fluxo da seqüência do pensamento não formulado nas construções lógicas, nas quais os pensamentos articuladamente formulados se expressam, tem uma estrutura especial própria"9. Para ele, o discurso interior é um estágio da estrutura sensorial da imagem, ainda sem a formulação lógica, de que o discurso necessita para ser entendido pelo outro: “ $\ldots$ as leis de construção do discurso interior são precisamente aquelas que existem na base de toda a variedade de leis que governam a construção da forma e a composição das obras de arte" 10 .

Ao relacionar a estrutura do discurso interior com a estrutura da forma cinematográfica, Eisenstein associa cinema à linguagem e ao seu desenvolvimento, afirmando que "o plano é a célula da montagem", similar ao pensamento de Vygotsky, para quem "a palavra é um microcosmo da consciência".

Eisenstein adota a teoria do discurso interno como estratégia e método de montagem para o desenvolvimento do filme. A montagem aqui entendida não como o trabalho de juntar os planos após a decupagem das cenas, mas como ato de construir, montar o filme em todo o seu processo.
Se os planos, ou seja, cada tomada com uma determinada duração, enquadrada de uma determinada forma - plano próximo, geral ou de meio conjunto - com um determinado movimento de cena ou de câmera são como palavras, fragmentos de um texto, ao usarmos as palavras geradoras, fragmentos de um contexto, numa dinâmica de uso, estaríamos, num outro movimento, buscando uma aproximação entre os dois processos: o da construção de um audiovisual e o da sua apropriação.

$\mathrm{O}$ cinema e o vídeo podem estimular uma forma de conhecimento ao acionar operações articuladas como memória, atenção, raciocínio, imaginação. "Por cognitivo, entendam-se todas as operações mentais implicadas na recepção, o armazenamento e o processamento da informação: percepção sensorial, memória, pensamento, aprendizagem" 11 .

As imagens em movimento provocam sensações e estimulam a percepção, nos fazem intuir e observar ao mesmo tempo a música, os sons, as cores, a disposição dentro do quadro, as sugestões vindas do extracampo. "Toda percepção é também pensamento, todo raciocínio é também intuição, toda observação é também invenção"12.

O audiovisual (cinema ou vídeo) é um meio eficaz na mediação do processo de apropriação do conhecimento, porque comporta em sua composição vários elementos de linguagem que propiciam uma compreensão em vários níveis. Assim, podem mais facilmente desencadear associações que levam aos sentidos e aos significados.

\footnotetext{
8. EISENSTEIN, Serguei. A forma do filme. Rio de Janeiro: Jorge Zahar, 1990. p.102.

9. EISENSTEIN, Serguei. A forma... op. cit. p.122.

10. Idem. Ibdem.

11. ARNHEIN, Rudolf. Arte e percepção visual. São Paulo: Pioneira, 1991. (Introdução).

12. ARNHEIN, Rudolf. Arte e... op. cit. (não paginado).
} 
Na vivência de uma dinâmica de desconstrução e construção coletiva, através de interações, os significados sociais e os sentidos de cada indivíduo afloram em uma nova construção, proporcionando uma compreensão mais ampla dos conteúdos que circulam no contexto.

\section{As formas de realização de um vídeo} ou filme fazem parte de uma cultura, um modo de ver e expressar o mundo, tornando-o uma espécie de espelho que, ao mesmo tempo, reflete e é memória de um processo, provoca novos debates e desencadeia ações, alimentando novos modos de conhecer.

A sua realização se dá através de um processo de construção/desconstrução constante, desde o roteiro até a montagem. Monta-se e desmonta-se e, neste desmontar e remontar, o filme ou o vídeo vai tomando forma com a participação da equipe: o trabalho do fotógrafo, dos atores, da produção, dos assistentes incide sobre a sua construção.

$\mathrm{O}$ roteiro é criado a partir da seleção temática, passa pelo resumo da história (story line) a ser desenvolvida no argumento. No decorrer da produção, na escolha de atores, de cenários, de equipe, de objetos de cena, aquilo que estava previsto no roteiro já começa a se transformar de acordo com as novas situações que se apresentam, como por exemplo: o modo como o ator imagina e interpreta tal personagem. Estes movimentos interferem e participam do processo de realização. As gravações são feitas em partes, fragmentadas, e a montagem implica a organização de pedaços, planos contendo imagens e sons gravados separadamente em situações diversas e desconectadas. Das ce- nas imaginadas às gravadas, decupadas e montadas percorre-se um trajeto de escolhas e seleção.

Assim também, ao assistir a um filme ou vídeo, cada espectador, de acordo com a sua imaginação e vivência, escolhe, interpreta e recompõe na sua memória as imagens e idéias apresentadas.

Ana Quiroga, referindo-se aos estudos de Pichon Rivière sobre processos educativos grupais, considera que "a tarefa criadora associa e integra o que até então se apresentava fragmentado e vai descobrindo nexos, relações. Ao mesmo tempo desestrutura formas previamente articuladas com vistas a uma nova organização"13.

Se o audiovisual instiga a imaginação e nos faz pensar, por que não estimular, através da percepção, uma vivência coletiva na qual o espectador se transforme em interlocutor para perceber, não o vídeo mas a partir do vídeo, a sua realidade?

Logo na primeira sequiência de $O \mathrm{pa}$ lácio da memória foi lançada uma sugestão de decifração, idéias que são posteriormente retomadas: a de processo colocada como a metalinguagem; o registro de um momento da gravação do próprio vídeo; o conflito, que aparece na música e na imagem em instrumentos de metal, cortando para o atabaque (imagem); terra, as camadas de compreensão sugeridas nas portas que se abrem; e ícones para a memorização que aparecem no espaço do palácio imaginário, repetindose em desenhos marcadores do percurso.

A forma do vídeo foi estruturada da seguinte maneira: na horizontal, uma divisão fechada, em blocos que se interpenetram, pontuadas pelos ícones marcadores; na vertical, camadas de compreensão em três planos, traduzidos como: a) a experiência com

13. QUIROGA, Ana P. O processo educativo segundo Paulo Freire e Pichon Rivière. (Seminário promovido pelo Instituto Pichon Rivière). Petrópolis: Vozes, 1989. p.17. 
os recursos apresentados; b) um processo de construção sendo desenvolvido; c) um pensamento que se expressa através de associações e metáforas.

Vale ressaltar dois aspectos que aparecem na organização das imagens e sons: uma, escolha intencional e outra, destituída de intenção, que se abre para o indeterminado, o aleatório, sugerindo outras possibilidades de leitura. Pensamos que, com essa organização, pode-se criar condições para o diálogo com alguns elementos de decifração e alguns espaços abertos.

Numa ação paralela que a princípio parece desconectada, dois personagens conflituosos, o ser e o ter, brigam por um espaço na tela: a personagem de uma professora que vende recursos pedagógicos, maravilhas da sociedade moderna, e um ator que se apresenta com um papel na mão, aquele que lhe foi imposto, tentando buscar o seu próprio papel, a idéia de sujeito de sua história, discutindo-se, desse modo, a educação bancária ${ }^{14}$, conforme o pensamento de Paulo Freire.

$\mathrm{O}$ ator, solto no chuvisco da tela, busca (ser) pelo seu próprio texto. O personagem da professora-garota-propaganda, presa no enquadramento, invade o espaço do ator. Recursos videográficos foram utilizados para trabalhar algumas idéias como a de espaço, tendo como metáfora a própria tela. $\mathrm{O}$ chuvisco é o espaço não preenchido pela imagem.

A citação do filme The wall ${ }^{15}$ (O muro) funciona também como metalinguagem. Discutindo a linguagem do filme, enquanto recurso, discutem-se também os conteúdos da imagem: adolescentes uniformizados e cabisbaixos caminham por um corredor em direção a uma máquina de moer carne, que os deforma.

Ao tentar a aproximação de um produto dialógico, buscou-se uma forma de realização na qual o diálogo estivesse contido já nos modos de produção, desde a pesquisa até a pós-produção. Outra tentativa de aproximação é a relação de diálogo estabelecida entre as múltiplas vozes que aparecem no vídeo através dos depoimentos. Cada uma das pessoas carrega um fragmento do discurso.

Esta busca do diálogo leva à compreensão de duas dimensões da prática que aparece ao longo do trabalho: a ação e a reflexão. E é com a intenção de refletir sobre a ação no vídeo, do vídeo, e a partir do vídeo que uma dinâmica com as características aqui apresentadas foi estimulada.

\section{UM EXERCÍCIO DE RECEPÇÃO}

Antes da exibição do vídeo para os 27 educadores, professores da rede pública e particular que participaram do evento, foi feita uma introdução, apontando alguns aspectos da linguagem cinematográfica: elementos de composição, criação do roteiro, fotografia, interpretação dos atores, montagem, pressupondo que, ao conhecer os códigos da linguagem, o interlocutor se torna mais apto ao diálogo.

Após a primeira exibição, cada pessoa escreveu numa folha em branco uma palavra, a que primeiro viesse à cabeça, e elas foram lidas, a princípio, aleatoriamente. Depois foram agrupadas por semelhanças de significados. Este procedimento é similar ao levantamento de palavras geradoras do método Paulo Freire ${ }^{16}$, segundo ele o ponto de

14. Paulo Freire, no livro Pedagogia do oprimido, em contraposição a uma concepção libertária de Educação, aponta uma concepção bancária de Educação, na qual os educandos seriam depósitos, que os educadores, adeptos desta concepçāo, vão enchendo de conteúdos. Pedagogia do oprimido. 17.ed., Rio de Janeiro: Paz e Terra, 1987. p. 61-63.

15. The wall (O muro). Filme baseado na música de Pink Floyd, Another brick in the wall (O outro tijolo no muro). 1979.

16. FREIRE, Paulo. Pedagogia do oprimido. op. cit. 
partida para o diálogo, pois cada palavra trazida para o coletivo é um pedaço da vida de cada pessoa e um canal que se abre para a participação. Para Vygotsky, "as palavras desempenham um papel central não só no desenvolvimento do pensamento, mas também na evolução histórica da consciência como um todo"17.

\section{PALAVRA E PENSAMENTO}

Quando Paulo Freire diz que "as palavras não são ocas, vazias, desvinculadas do seu contexto" há uma espécie de ressonância com o pensamento de Vygotsky: "Uma palavra desprovida de pensamento é uma coisa morta". Podemos completar com Bakhtin: "Aquele que apreende a enunciação de outrem não é um ser mudo, privado da palavra, mas ao contrário um ser cheio de palavras interiores" 18 .

No sistema Paulo Freire, os temas levantados, a partir das palavras que emergem do grupo, são decodificados e relacionados a um contexto, dando-lhes uma dimensão existencial. Ao dimensionarmos as palavras que ganham significado e sentido, pensamos sobre a nossa existência: “(...) o tema gerador não se encontra nos homens isolados da realidade, nem tampouco na realidade separada dos homens. Só pode ser compreendido nas relações homem-mundo"'19.

As palavras que apareceram no exercício com os educadores presentes foram: antagonismo, pano azul, ser (três vezes), angústia, construção, desenvolvimento, construir (três vezes), desordenar, crescer, imaginação (duas vezes), luz, busca, concretização, liberdade (quatro vezes), expressão, interação, metodologia, material.
Algumas palavras nos passam a idéia de processo, como: construir, desenvolvimento, busca, interação, metodologia, desordenar, concretização. Outras estão num plano existencial, como: ser, liberdade, crescer, antagonismo, angústia. E outras, ainda, como material, luz, pano azul indicam aspectos materiais.

As associações feitas através das palavras estão relacionadas com o vídeo e com a vida de cada um, ou seja, a palavra é o elemento de ligação da experiência audiovisual com a experiência pessoal e social dos elementos do grupo.

"Provindo de áreas inconscientes do nosso ser ou talvez pré-inconscientes, as associações compõem a essência do nosso mundo imaginativo. São correspondências, conjecturas à base de semelhanças, ressonâncias íntimas em cada um de nós com experiências anteriores e com todo um sentimento de vida" 20 .

O debate iniciou com a expressão $p a-$ no azul: Ao se apresentar, a pessoa que a escrevera descobriu que havia associado "pano azul" à sua experiência como contadora de histórias para crianças, pois utiliza objetos para desenvolver a sua narração. Um pano azul que, usando a imaginação, se transforma em qualquer outro objeto como uma vassoura, uma arma, uma tipóia para um braço quebrado. Outra professora, com a palavra angústia, expressou sua preocupação com a inserção das novas tecnologias na educação, em contraposição aos que escreveram a palavra liberdade, $\mathrm{e}$ que centravam seu pensamento exatamente na educação. 
Na discussão que se desenvolveu a partir daí, estavam as idéias que apareceram no vídeo e as experiências e preocupações de cada participante.

"Às vezes é preciso restaurar as partes perdidas, encontrar tudo o que não se vê na imagem, tudo o que foi subtraído dela para torná-la interessante. Mas, às vezes, ao contrário, é preciso fazer buracos, introduzir vazios e espaços em branco, refazer a imagem, suprimir dela muitas coisas que foram acrescentadas para nos fazer crer que víamos tudo. É preciso dividir ou esvaziar para ver o inteiro"21.

\section{DIÁLOGO E EXPERIÊNCIAS}

Quando assistiram ao vídeo pela segunda vez, as pessoas se surpreenderam: "É como se o vídeo tivesse ficado transparente", comentou uma das professoras. "A reorganização espaço-temporal e a realidade especialmente construída no interior do filme são justamente os elementos discursivos que tornam possível a percepção daquilo que não é imediatamente visível na nossa experiência direta do mundo"22.

Essa transparência a que a professora se referiu, ou seja, o ter tornado explícito o que estava implícito, foi possível porque as pessoas conheciam minimamente os códigos audiovisuais para uma leitura articulada com a linguagem. As múltiplas observações apresentadas com diferentes pontos de vista alertaram cada espectador para aspectos não percebidos na primeira leitura.

$\mathrm{Na}$ tentativa de entender como se dá a relação entre espectador, interlocutor e o audiovisual, através de dinâmica relacionada à construção do trabalho, observaram-se alguns aspectos que emergiram do processo.

A interlocução, que se deu a partir das palavras vindas de múltiplas experiências relacionadas com o que as pessoas perceberam no vídeo, revelou não só os conteúdos implícitos no vídeo, mas os conteúdos implícitos no contexto.

$\mathrm{O}$ formato em rede de um hipertexto permite que o contexto se revele através de palavras-chave com referências cruzadas e uma leitura não linear. Para Pierre Lévy, hipertextos são mundos de significação: "Tecnicamente um hipertexto é um conjunto de nós ligados por conexões" 23 .

Os fragmentos de experiências de vida, misturados às experiências relatadas no vídeo, constituíram uma rede de informações que se assemelha a um hipertexto, um quebra-cabeças com uma organização própria e informação subjacente, que foi sendo montado na medida da sua desmontagem, criando vários desdobramentos e múltiplas combinatórias.

"Na visão contemporânea, os processos de conhecimento percorrem caminhos labirínticos, metaforizando as estruturas mentais. Neste universo fragmentário, multíplice, diverso e irregular, não se anda em linha reta. São nas bifurcações do caminho que se encontram as possibilidades de expansão, num processo em que decifrar é construir espaços" 24 .

É interessante observar também que entre as palavras vindas da platéia, logo após a primeira exibição do vídeo, percebemos três grupos: do processo, do existencial

21. DELEUZE, Gilles, Cinema II. Imagem tempo. São Paulo: Brasiliense, 1990, p.32.

22. XAVIER, Ismail. O discurso cinematográfico. Rio de Janeiro: Paz e Terra, 1984. p.44.

23. LÉVY, Pierre. As tecnologias da inteligência: o futuro do pensamento na era da informática. Rio de Janeiro: Editora 34 , 1993. p.33.

24. FONSECA, Maria Teresa Azevedo da. Três imagens-passagens expansões da poética no filme $A$ última tempestade, de Peter Grenaway, 1995. (mimeo) 
e dos recursos materiais. O vídeo foi organizado em três camadas: a dos recursos propriamente ditos; a do processo (de aprendizagem, de construção, de criação); e a do pensamento que norteia o trabalho contido no intertexto, em metáforas e associações com imagens, apoiadas pelas reflexões de Paulo Freire. Quando escreveram aleatoriamente as palavras, os participantes desconheciam esta estrutura; daí concluímos que, intuitivamente, houve também uma apreensão da forma do vídeo.

Cada imagem e cada depoimento, no vídeo, é a síntese de um pensamento que

Resumo: $\mathrm{O}$ artigo trata de um exercício de leitura e desconstrução do vídeo $O$ palácio $d a$ memória. Baseia-se na relação pensamentolinguagem, destacando o papel da palavra na construção do não-verbal, na constituição do discurso interior e da consciência (M. Bakhtin e Vygotsky) e no conceito de palavras-geradoras de Paulo Freire, para relatar a experiência realizada com educadores da rede de ensino na recepção do vídeo. Conclui que esse tipo de análise permite maior aproximação dos contextos em que se realiza a recepção.

Palavras-chave: linguagem-pensamento, leitura, recepção, palavra-geradora, $O$ palácio da memória está por detrás destas falas e destas imagens. Nesta rede intrincada de diálogos existem vários discursos: o de cada uma das pessoas que se apresentou no vídeo; o do realizador que juntou cada fragmento e construiu um outro discurso; e o do receptor que, ao ler os discursos de outrem através do discurso do realizador, construiu seu próprio discurso.

Quando foi visto pela segunda vez, cada fragmento se tornou uma passagem para outras informações, contidas ou não na imagem, dependendo dos olhos daqueles que a observavam.

Abstract: The article deals with an exercise of reading and deconstructing the video $O$ palácio da memória (Memory palace). It is based on the relationship between thought-language, stressing the role the word has in constructing the non-verbal, on the constitution of interior discourse and of conscience (M. Bakhtin e Vygotsky) and on Paulo Freire's concept of generating words, in order to report on an experience carried out with public teaching educators on video reception. The article concludes that this type of analysis allows for a greater approximation between the contexts in which reception is performed.

Key words: language-thought, reading, reception, word-generator, $O$ palácio da memória 